\title{
GLYCEMIC PROFILE OF PERSONS WITH DIABETES MELLITUS IN A HOME BLOOD GLUCOSE SELF-MONITORING PROGRAM
}

\author{
Vívian Saraiva Veras ${ }^{1}$, Carla Regina de Sousa Teixeira², Manoel Antônio dos Santos ${ }^{3}$, Maria Teresa da Costa \\ Gonçalves Torquato ${ }^{4}$, Flávia Fernanda Luchetti Rodrigues ${ }^{5}$, Maria Lúcia Zanetti ${ }^{6}$
}

\footnotetext{
${ }^{1}$ Doctoral student in Sciences on the Postgraduate Program in Basic Nursing, of the Ribeirão Preto School of Nursing (EERP) of the Universidade de São Paulo (USP). Ribeirão Preto, São Paulo, Brazil. E-mail: vivianveras@hotmail.com

${ }^{2}$ Ph.D in Nursing. Associate Professor of the Department of General and Specialized Nursing, EERP/USP. Ribeirão Preto, São Paulo, Brazil. E-mail: carlarst@eerp.usp.br

${ }^{3}$ Ph.D. in Psychology. Associate Professor III of the Department of Psychology, Faculty of Philosophy, Sciences and Languages, Ribeirão Preto, USP. Ribeirão Preto, São Paulo, Brazil. E-mail: masantos@ffclrp.usp.br

${ }^{4}$ Ph.D. in Internal Medicine. Ribeirão Preto, São Paulo, Brazil. Email: tttorquato@globo.com

${ }^{5}$ Doctoral student in Sciences, Postgraduate Program in Basic Nursing, EERP/USP. Ribeirão Preto, São Paulo, Brazil. E-mail: flavialuchetti@gmail.com

${ }^{6}$ Ph.D. in Nursing. Associate Professor III of the Department of General and Specialized Nursing, EERP/USP. Ribeirão Preto, São Paulo, Brazil. E-mail: zaneetti@ffclrp.usp.br
}

\begin{abstract}
This retrospective study aimed to analyze the blood capillary glucose at home and the number of hypoglycemic and hyperglycemic episodes presented by persons with Diabetes Mellitus, at the start of, and at least six months after beginning to participate in, the Blood Glucose Self-Monitoring Program. A total of 97 service users with diabetes participated, from a municipality in the nonMetropolitan region of the state of São Paulo. Two spreadsheets were used for recording the blood glucose values at the start of the Program and after a minimum of six months. It was observed that there was an improvement in the postprandial blood glucose level (lunch) and in the very early morning $(\mathrm{p}<0.05)$. In relation to hypoglycemic episodes, there was a slight improvement in the mean, from 0.75 at the beginning to 0.49 after a minimum of six months' participation in the Program. The reduction of hyperglycemic episodes was, in the beginning, of $27.88 \%$ episodes and, at a minimum of six months' participation in the Program, of $29.15 \%$ episodes.
\end{abstract}

DESCRIPTORS: Diabetes mellitus. Self-monitoring of blood glucose. Blood glucose. Nursing.

\section{PERFIL GLICÊMICO DE PESSOAS COM DIABETES MELLITUS EM UM PROGRAMA DE AUTOMONITORIZAÇÃO DA GLICEMIA CAPILAR NO DOMICÍLIO}

RESUMO: Estudo retrospectivo que teve como objetivo analisar a glicemia capilar no domicílio, o número de episódios de hipoglicemias e hiperglicemias apresentadas pelas pessoas com Diabetes Mellitus, no início e, no mínimo, após seis meses de participação no Programa de Automonitorização da Glicemia Capilar no domicílio. Participaram 97 usuários com diabetes, oriundos de um município do interior paulista. Foram utilizadas duas planilhas para registro dos valores de glicemia capilar no início do Programa e, após, no mínimo seis meses. Constatou-se que houve melhora nas glicemias pós-prandial (almoço) e durante a madrugada ( $<<0,05)$. Quanto aos episódios de hipoglicemias houve discreta melhora na média, de 0,75 no início para 0,49 depois de no mínimo seis meses de participação no Programa. A redução dos episódios de hiperglicemia foi, no início, de 27,88\% episódios e, no mínimo, seis meses de participação no Programa, de 29,15\% episódios. DESCRITORES: Diabetes mellitus. Automonitorização da glicemia. Glicemia. Enfermagem.

\section{PERFIL GLICÉMICO DE LAS PERSONAS CON DIABETES MELLITUS EN UN PROGRAMA DE AUTOMONITORIZACIÓN DE CONTROL DE LA GLICEMIA EN CASA}

\begin{abstract}
RESUMEN: Este estudio retrospectivo tuvo como objetivo analizar la glucosa en sangre capilar en casa, el número de episodios de hipoglicemia y hiperglicemia presentada por las personas con Diabetes Mellitus al inicio del estudio y por lo menos seis meses después de su participación en el programa de automonitorización de glucosa en sangre capilar en casa. Participaron 97 usuarios con diabetes, de una ciudad en el interior de São Paulo. Dos puntuaciones se utilizaron para registrar los valores de glucosa en sangre al comienzo del programa y después de al menos seis meses. Se encontró una mejoría de la glicemia posprandial (almuerzo) y durante la noche $(p<0,05)$. En cuanto a los episodios de hipoglicemia hubo una ligera mejoría en promedio de 0,75 al inicio del estudio a 0,49 después de al menos seis meses de la participación en el Programa. La reducción de los episodios de hiperglicemia fue, al inicio, 27,88\% y, al menos, seis meses de participación en el programa, de 29,15\% de los episodios.
\end{abstract}

DESCRIPTORES: Diabetes mellitus. Automonitorización de la glucosa sanguínea. Glicemia. Enfermería. 


\section{INTRODUCTION}

The Self-Monitoring of Blood Glucose (SMBG) is considered an integral part of the set of interventions in Diabetes Mellitus (DM), and an essential component of an effective therapeutic strategy for the appropriate control of the disease. ${ }^{1}$ This procedure allows the person with DM to evaluate their individual response to the therapy instituted, also allowing them to evaluate whether the recommended glycemic goals are being effectively achieved. In addition to this, the construction of a glycemic profile facilitates the investigation of the attitudes of the person with DM, which can contribute to the presentation of hypoglycemic or hyperglycemic episodes, as well as other complications of the disease. ${ }^{1}$

Prospective clinical studies, such as the Diabetes Control and Complications Trial (DCCT), ${ }^{2}$ which investigated persons with type $1 \mathrm{DM}$, and the United Kingdom Prospective Diabetes Study Group (UKPDS), ${ }^{3}$ with persons with type 2 DM, documented the benefits in preventing the chronic complications through tight glycemic control.

The obtaining of good metabolic control includes the appropriate frequency for monitoring blood glucose, nutritional therapy, regular physical exercise, pharmacological therapeutic regimens, information regarding the prevention and treatment of the acute and chronic complications, and the periodic evaluation of the treatment's objectives. ${ }^{2}$ SMBG in the home stands out among the interventions for maintaining good glycemic and metabolic control.

The international literature corroborates the use of SMBG in people with type $1 \mathrm{DM}^{4}$ and type 2 DM, using ${ }^{5}$ or not insulin therapy ${ }^{6}$ and in the case of gestational DM. ${ }^{7}$ Observational and clinical studies, which used investigation protocols, and meta-analysis studies on the importance of self-monitoring of blood glucose in persons with type $2 \mathrm{DM}$ who do not use insulin ${ }^{8}$ show that this practice is associated with improvements in the levels of HbA1c. Although further studies are necessary in order to establish the ideal frequencies for blood glucose tests, the studies currently available can be used in order to define some recommendations in the guidance of people with DM and of health professionals, regarding the frequency of SMBG. ${ }^{9}$

However, even recognizing that SMBG is a fundamental part of the treatment, it is known that many people with DM, for economic, social or psychological reasons, do not undertake selfmonitoring. ${ }^{10}$ One can add to this, also, that many public and private institutions which care for people with DM still lack glucometers and reagent strips for practicing SMBG at home. Associated with this lack of coverage for these procedures, which are so essential for the control of DM, are other obstacles, which need to be overcome if strategies for encouragement of blood glucose control are to be successful. ${ }^{11}$

In line with the recommendations of the American Diabetes Association and of the Plan for Reorganization of Arterial Hypertension and Diabetes Mellitus, the Municipal Health Department of Ribeirão Preto (SMS-RP, in Portuguese), a municipality in the non-metropolitan region of the State of São Paulo, implemented SMBG Program. This Program is part of the project of Municipal Law N. 10,299 of 2004, published in the Official Gazette - the Official Organ of the Municipality of Ribeirão Preto, SP, annal XXXIII, N. 7348, of $25^{\text {th }}$ August 2005, which relates to the distribution free of charge of medications - and materials which are necessary for their administration - and the monitoring of blood glucose of service users with DM, registered on diabetes education programs.

In this regard, it is urgent and necessary to evaluate what the benefits are for the service users with DM registered on the SMBG Program relating to improvement in their glycemic and metabolic control. Equally, studies of this nature can provide important support for redirecting the actions in primary care, in relation to the materials made available for control of DM.

In the light of the above, this study aims to analyze the blood glucose at home, and the number of hypoglycemic and hyperglycemic episodes presented by the service users with DM, at the start of, and after six months' participation in, the above-mentioned Program.

\section{METHOD}

This retrospective study was undertaken in four Primary Healthcare Centers (PHC) in the West district of the SMS-RP. The study population was made up of 359 service users with DM, attended in the above-mentioned Health Centers and registered on the HSMBG Program. This number was obtained through consulting the System for Control of Dispensation of Strategic Materials (SIE, in Portuguese) for the service users who were 
registered in the period $1^{\text {st }}$ November $2005-31^{\text {st }}$ December 2008. It included service users with type 1 and 2 DM, registered on the Program, who had two spreadsheets for glycemic profile (one for the start of the SMBG Program, and one at a minimum of six months' participation). A total of 263 service users with DM were excluded, 100 because they lacked spreadsheets for the beginning and a minimum of six months after entering the Program; 49 for whom hospital records were not found; 108 who had no records of the laboratory tests in the health records prior to participation and/or six months after entering the Program; five persons had died, and one had quit the Program during the evaluation period.

The sample was made up of 97 service users with DM who met the inclusion criteria. For elaborating the data collection instrument, the researchers selected the demographic variables (sex and age), clinical variables (duration of the disease, comorbidities, medications in use for $\mathrm{DM}$ and the health institution which monitors them), and variables related to the glycemic profile (fasting glycemic values, values after breakfast, before and after lunch, before and after dinner and in the very early hours of the morning). In order to obtain the data, following obtaining approval from the Research Ethics Committee, the researcher approached the selected PHCs and contacted the managers of each unit, explaining the study objectives. Next, she approached the PHC Pharmacy and requested the spreadsheets for the glycemic profile and the signed agreement from the pharmacist or the pharmacy assistant. Patients participating in the SMBG Program have to sign an agreement in order to receive materials from the pharmacy.

Once in possession of the spreadsheets, the collection of data referent to the glycemic profile was initiated. The data collected refer to the blood glucose values at home over one month, contained in the spreadsheets for the glycemic profile at the beginning of, and after a minimum of six months' participation in, the Program. Following that, data were collected from the signed agreement (date of initiating participation in the SMBG Program). The data were transcribed for the data collection spreadsheets constructed by the researcher.

Data collection was undertaken between May and June 2009. The information obtained from the service users with DM was organized in a Microsoft Excel spreadsheet (version XP), through double keying and later validation.
Descriptive statistics was used for data analysis, with the aim of summarizing a series of values of the same nature, allowing a global view of the values' variation. The data were organized and described through tables, graphs and descriptive measurements.

In order to ascertain whether there were differences between the periods which make up the present study - at the beginning of the SMBG Program and at a minimum of six months' participation, the paired Student $t$-test for paired quantitative data was used. In this case, the pairing can be observed through the obtaining of the respective measurements in a single individual at two distinct points in time. This test has as its null hypothesis that the difference between the measurements obtained in both periods is equal to zero. The differences observed were considered significant when the minimum level of significance ( $p$-value) was below 0.05 . For undertaking this procedure, the PROC TTEST from the SAS $₫ 9.0$ software was used. The graphs were constructed using the R Software. The project was approved by the Ethics Committee of the Ribeirão Preto School of Nursing, of the University of São Paulo, on $20^{\text {th }}$ December 2007, under protocol $n$. 0866/2007.

\section{RESULTS}

Of the 97 (100\%) subjects investigated, the majority were female $(73.2 \%)$, aged between 10 and 92 years old, with a predominance of the age range 60 - 69 years old (31.9\%). Of the 97 subjects, only seven had a record of the disease's duration, with this varying between one year five months and 28 years. Regarding comorbidities, $54.2 \%$ of the subjects had high blood pressure and 22.8\% had high blood pressure and dyslipidemia, and $23 \%$ had other diseases. In relation to the use of medications, 54.2\% used an oral agent (Biguanide) in association with insulin; $19.8 \%$, only insulin and $17.7 \%$, oral agents used in associated with insulin (Biguanide and Sulfonylurea) for the control of DM; $8.3 \%$ used other associations. The majority $(85.1 \%)$ were monitored for the control of DM in PHCs.

In relation to the values of blood glucose at home, in accordance with the times of meals, it was observed that there was an improvement in the postprandial blood capillary glucose values (lunch) and during the very early morning $(\mathrm{p}<0.05)$, after a minimum of six months' participation in the Program (Table 1). 
Table 1 - Distribution of the service users with DM registered on the Home Self-Monitoring of Blood Capillary Glucose Program of the SMS-RP, by glycemic values, at the start of, and at a minimum of six months after participation in, the Program. Ribeirão Preto-SP, November 2005 - December 2008

\begin{tabular}{|c|c|c|c|c|c|c|c|}
\hline SMBG Intervals & Period & $\mathbf{n}$ & Means & $\begin{array}{l}\text { Standard- } \\
\text { deviation }\end{array}$ & Differences & CI $(95 \%)$ & P-value* \\
\hline \multirow{2}{*}{ Fasting Blood Glucose } & Start of SMBG & 88 & 145.65 & 48.24 & \multirow{2}{*}{8.4943} & \multirow{2}{*}{$(-0.826 ; 17.814)$} & \multirow{2}{*}{0.0735} \\
\hline & Min. 6 months of SMBG & 88 & 137.16 & 43.29 & & & \\
\hline \multirow{2}{*}{ After breakfast } & Start of SMBG & 22 & 190.23 & 75.41 & \multirow{2}{*}{21.659} & \multirow{2}{*}{$(-16.45 ; 59.76)$} & \multirow{2}{*}{0.2504} \\
\hline & Min. 6 months of SMBG & 22 & 168.57 & 68.09 & & & \\
\hline \multirow{2}{*}{ Before lunch } & Start of SMBG & 52 & 172.03 & 77.26 & \multirow{2}{*}{17.279} & \multirow{2}{*}{$(-6.318 ; 40.875)$} & \multirow{2}{*}{0.1477} \\
\hline & Min. 6 months of SMBG & 52 & 154.75 & 51.14 & & & \\
\hline \multirow{2}{*}{ After lunch } & Start of SMBG & 58 & 188.90 & 74.10 & \multirow{2}{*}{24.207} & \multirow{2}{*}{$(3.5068 ; 44.853)$} & \multirow{2}{*}{0.0224} \\
\hline & Min. 6 months of SMBG & 58 & 164.69 & 57.43 & & & \\
\hline \multirow{2}{*}{ Before dinner } & Start of SMBG & 32 & 159.17 & 61.36 & \multirow{2}{*}{-17.190} & \multirow{2}{*}{$(-44.05 ; 9.6766)$} & \multirow{2}{*}{0.2015} \\
\hline & Min. 6 months of SMBG & 32 & 176.36 & 74.29 & & & \\
\hline \multirow{2}{*}{ After dinner } & Start of SMBG & 51 & 189.53 & 67.08 & \multirow{2}{*}{15.824} & \multirow{2}{*}{$(-3.471 ; 35.118)$} & \multirow{2}{*}{0.1058} \\
\hline & Min. 6 months of SMBG & 51 & 173.71 & 47.78 & & & \\
\hline \multirow{2}{*}{ Very early morning } & Start of SMBG & 14 & 181.82 & 66.70 & \multirow{2}{*}{37.357} & \multirow{2}{*}{$(9.2745 ; 65.44)$} & \multirow{2}{*}{0.0170} \\
\hline & Min. 6 months of SMBG & 14 & 144.46 & 73.44 & & & \\
\hline
\end{tabular}

${ }^{*}$ P-value referent to the paired Student $\mathrm{t}$ test.

It stands out that there was a reduction in the blood glucose values after the implementation of the SMBG Program, apart from those taken before dinner. In comparing the glycemic profile presented at the beginning and after a minimum of six months' participation in the Program, a significant reduction was obtained in the postprandial glycemic values (lunch) and during the very early morning $(\mathrm{p}<0.05)$, as shown in figure 1 .

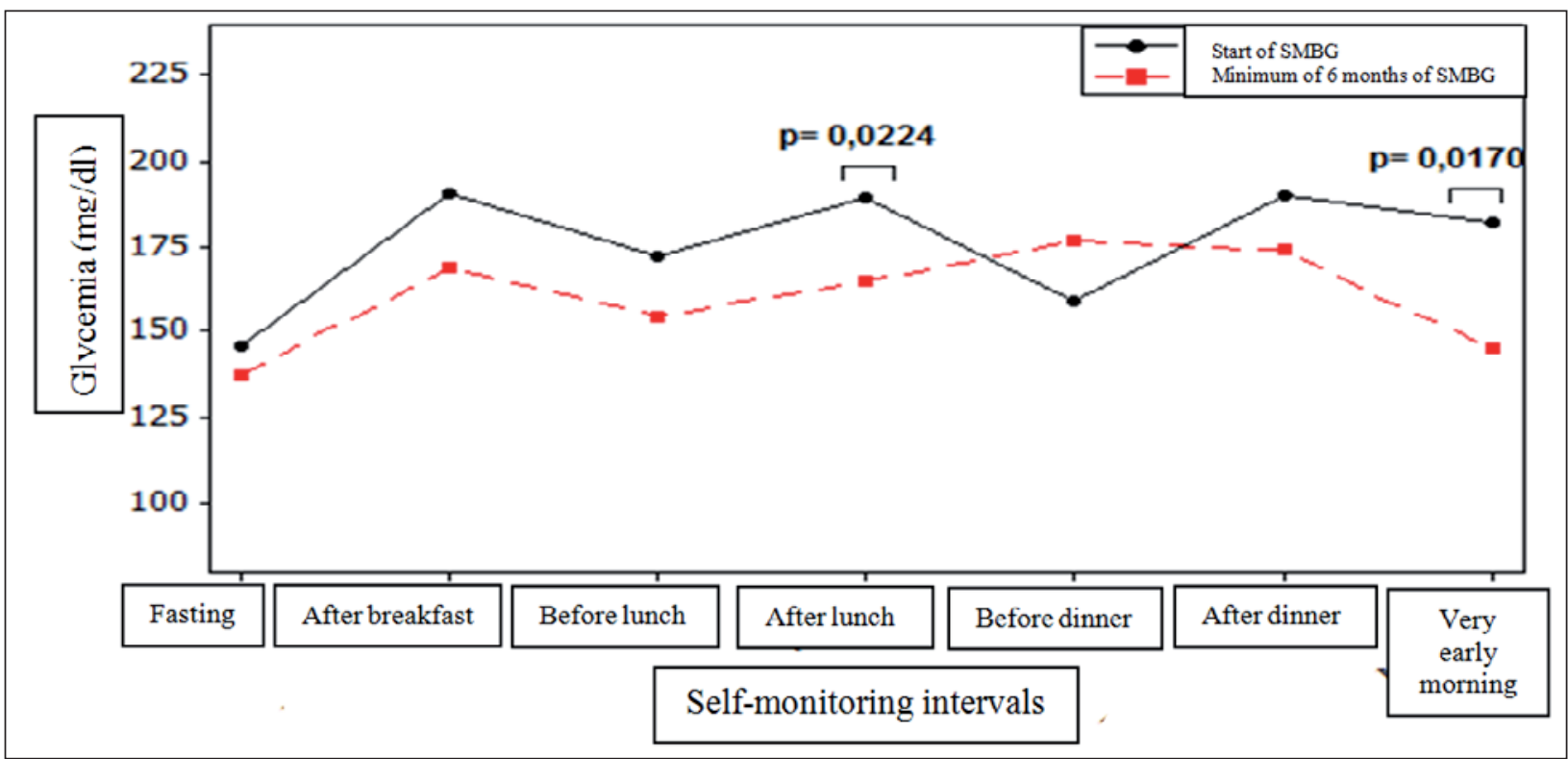

Figure 1 - Glycemic profile of the service users with DM registered on the Self-Monitoring Blood Glucose Program of the SMS-RP, in accordance with the different self-monitoring intervals, at the beginning of and at a minimum of six months' participation in, the Program 
In relation to the number of hypoglycemic episodes, there was a slight improvement in the mean, from 0.75 at the start to 0.49 after a minimum of six months' participation in the Program. The reduction of hyperglycemic episodes was, in the beginning, of $27.88 \%$ episodes and after a minimum of six months' participation in the program, of $29.15 \%$ episodes. Therefore, these were not considered statistically significant $(p=1.000)$ (Table 2).

Table 2 - Distribution of the service users with DM registered on the Home Self-Monitoring Blood Glucose Program of the SMS-RP, according to the number of hypoglycemic and hyperglycemic episodes, at the beginning of and after a minimum of six months' participation in, the Program. Ribeirão Preto-SP, November 2005 - December 2008

\begin{tabular}{clcccccc}
\hline Variables & \multicolumn{1}{c}{ Period } & $\mathbf{n}$ & Means & $\begin{array}{c}\text { Standard- } \\
\text { deviation }\end{array}$ & Differences & CI (95\%) & P-value* \\
\hline Hypoglycemia & Start of SMBG & 97 & 0.75 & 2.34 & 0.2577 & $(-0.228 ; 0.7439)$ & 0.2953 \\
& Min. 6 months of the SMBG & 97 & 0.49 & 1.09 & & & \\
Hyperglycemia & Start of SMBG & 97 & 11.48 & 10.35 & 0 & $(-2.407 ; 2.4075)$ & 1.0000 \\
& Min. 6 months of the SMBG & 97 & 11.48 & 14.79 & & & \\
\hline
\end{tabular}

${ }^{*}$ P-value referent to the Student $t$ test.

\section{DISCUSSION}

The results obtained showed that the implementation of the SMBG Program improved the glycemic values of the service users with DM in the following times: post-prandial (lunch) and very early in the morning. For the Program to achieve excellence, the need is emphasized for the implementation of an educational program such that people with DM may be trained to use the glucometers, to understand the reasons which justify the times at which the test should be undertaken, to interpret the blood glucose results and to recognize when an action needs to be taken according to the glycemic values. ${ }^{12}$

In this regard, it is necessary to invest in efficient communication strategies between the person with DM and the professionals of the health team, so that the SMBG may be undertaken at home effectively and that the person with DM may continue motivated for practicing SMBG. The people with DM must have a direct line for contact with the health professionals relating to the blood glucose results at home. In her turn, the professional from the health team must receive the necessary training in DM to interpret the results and suggest possible changes in the treatment. ${ }^{13}$

Self-monitoring of blood glucose is an essential resource for people with type 1 and type $2 \mathrm{DM}$ to have good control, so long as it is used consistently, with the rationalization of the costs and with the frequency of the testing specifically indicated for each clinical condition. The main criticism made in the international literature is the difficulty which the person with DM has in taking decisions in the light of the results of the SMBG undertaken at home. Indeed, without appropriate education in DM, and practical guidance regarding what to do with the test results, SMBG at home can bring more harm than good for the health system. ${ }^{14}$

Unlike measurements of $\mathrm{HbA1c}$, SMBG is episodic. The blood glucose is measured at only one point, in real time. Hence, determining the times for SMBG is of great importance, taking into account that the date and time must be correctly calibrated on the glucometer in order to allow the correct interpretation of results. It is important for the professional from the health team and the person with DM to define glucose goals in each case and to propose strategies for achieving them. ${ }^{15-16}$

It is easier to achieve glycemic control if the persons with DM undertake the glycemic profile at different times throughout the day, with information regarding fasting, pre-prandial and postprandial blood glucose levels. The SMBG undertaken at different times and on different days can provide a reliable depiction of daily glycemic excursions, as well as avoiding the need to undertake tests of various times on a single day. ${ }^{12}$ However, the data obtained in the present study showed that the assessments of blood glucose levels at home were undertaken with greater frequency while fasting by the service users with DM and with a much reduced frequency at postprandial times.

Epidemiological studies suggest that postprandial hyperglycemia is the most predictive for adverse cardiovascular events. ${ }^{17}$ The verification of postprandial glycemia, therefore, allows a more ac- 
curate analysis of the daily glycemic profile of each person with DM, which is fundamental for better guidance of the health team regarding the possible means for correction of therapeutic conduct.

Guidelines recommend that the undertaking of SMBG at pre-and post-prandial times must be included in the planning of DM treatment, so as to obtain a better 24-hour glycemic profile. ${ }^{18}$ Even taking into account that some prescriptions for undertaking the tests are at fixed times, the persons with DM must be encouraged to measure the blood glucose at the times of the main meals. Studies which undertook a blood glucose test at the time of the main meals showed an improvement in the HbA1c. ${ }^{19}$

In spite of the $\mathrm{HbA1c}$ being considered the gold standard for long-term monitoring of glycemic control in DM, its complementation with the information obtained from the SMBG places the person with DM closer to the ideal glycemic control. SMBG can clarify which aspects of the blood glucose control are more problematic for the person with DM, whether fasting, or at the pre- or post-prandial times. This information can, therefore, be used for undertaking the appropriate adjustments in the dietary plan, physical activity, and drug therapy. Glycemic excursions are common, even among people with compensated DM. These changes are easily identified by regular SMBG tests before and after meals.

Randomized studies evidence that if the SMBG is effectively translated into action, there is an improvement in the glycemic profile. The data were more conclusive for people with DM using insulin, in which the SMBG is part of a complete regimen for improving blood glucose levels and, through this, to help in reducing complications resulting from the disease. ${ }^{20}$

In relation to the number of hypoglycemic episodes, a slight improvement was obtained in the mean after a minimum of six months' participation in the SMBG Program. However, the mean of the hyperglycemias remained equal in both of the evaluations. Prospective and randomized clinical studies have shown that the intensive control of the glycemia increases the risks of hypoglycemia. However, the benefits of glycemic control are greater than the risks presented in the hypoglycemic episodes. As a result, it is recommended that intensive glycemic control should be undertaken carefully and under strict control..$^{2-3}$

Hypoglycemia is a concern both for people with type 1 and type $2 \mathrm{DM}$ receiving treatment with insulin and/or oral agents. In one study using the Continuous Glucose Monitor System (CGMS) in older adults with type $2 \mathrm{DM}$, there were no reports of symptoms of hypoglycemia. However, $80 \%$ had glycemic values below $50 \mathrm{mg} / \mathrm{dL}(2.8$ $\mathrm{mmol} / \mathrm{L}$ ), in at least one time when monitoring was undertaken. ${ }^{21}$ SMBG constituted a means of identifying hypoglycemic events, allowing immediate treatment and the altering of therapeutic regimens in order to achieve better glycemic control, minimizing the risk of future hypoglycemia.

Our study showed that persons with DM receiving intensive treatment with insulin and who undertook SMBG appropriately significantly reduced their levels of $\mathrm{HbA1c}$. However, an increase was ascertained in the frequency of hypoglycemic episodes, above all due to the lack of technological resources which could allow the continuous monitoring of the glucose over the day and, in this way, predict the hypoglycemic events. ${ }^{2}$

The data obtained in the present study showed that the users registered in the four Health Centers undertook the measurements of blood glucose sporadically in the very early morning. In this regard, the service users registered on the Program needs encouragement in relation to the importance of the regular assessment of blood glucose at home in the very early morning, when necessary.

The literature indicates that checking blood glucose during the night is not usual, which hinders the documentation of hypo- or hyper-glycemic excursions during the night or the beginning of the morning, such as the "Dawn phenomenon" and the "Somogyi Effect". The control of these metabolic effects can improve the patients' quality of life and reduce the development of complications. ${ }^{1,20}$

The results showed that, in spite of the reduction in the postprandial blood glucose levels (lunch) and in the very early morning, these continue outside the parameters of normality, evidencing the complexity of the care for the person with DM. On the other hand, it is necessary to consider the clinical importance of self-monitoring of blood glucose at home, which can lead to the self-responsibilization of the person with diabetes for their self-care. ${ }^{22-23}$

\section{CONCLUSION}

The implementation of the SMBG Program of the SMS-RP brought benefits in the glycemic control of the persons with DM. There was a 
reduction of the blood glucose values after the SMBG Program, apart from prior to dinner. In relation to the number of hypoglycemic episodes, a slight improvement in the mean was noted after a minimum of six months' participation in the Program. However, the hyperglycemic events mean remained equal in the two evaluations.

Among the limitations found, emphasis is placed on the difficulties in locating the spreadsheets for the glycemic profile in the health units and the lack of data referent to the rates of abandonment of the program on the part of the users.

The implementation of an educational program geared towards users registered on the SMBG Program in the above-mentioned study place is recommended, reinforcing the need to increase the measurements of glycemia in the very early morning.

\section{REFERENCES}

1. American Diabetes Association: tests of glycemia in diabetes. Diabetes Care. 2004; 27(suppl):S91-3.

2. Diabetes Control and Complications Trial - DCCT. Research group: the effect of intensive treatment of diabetes on the development and progression of long term complications in IDDM. N Engl J Med. 1993 Sep; 329(14):977-86.

3. United Kingdom Prospective Diabetes Study Group. Effect of intensive blood-glucose control with metformin on complications in overweight patients with type 2 diabetes: UKPDS 34. Lancet. 1998 Sep; 352(9131):854-65.

4. Zoffmann V, Lauritzen T. Guided self-determination improves life skills with Type 1 diabetes and A1C in randomized controlled trial. Patient Educ Couns. 2006 Dec; 64(1-):78-6.

5. Chen HS, Wu TE, Jap TS, Lin SH, Hsiao LC, Lin HD. Improvement of glycemia control in subjects with type 2 diabetes by self-monitoring of blood glucose: comparison of two management programs adjusting bedtime insulin dosage. Diabetes Obes Metab. 2008 Jan; 10(1):34-40.

6. Farmer A, Wade A, Goyder E, Yudkin P, French $\mathrm{D}$, Craven A, et al. Impact of self monitoring of blood glucose in the management of patients with non-insulin treated diabetes: open parallel group randomised trial. Br Med J. 2007 Jul; 335(7611):105-6.

7. Kitzmillher JL, Block JM, Brown FM, Catalano PM, Conway DL, Coustan DR, et al. Managing preexisting diabetes for pregnancy: summary of evidence and consensus recommendations for care. Diabetes Care. 2008 Mai; 31(5):1060-79.

8. Towfigh A, Romanova M, Weinreb JE, Munjas B, Suttorp MJ, Zhou A, et al. Self-monitoring of blood glucose levels in patients with type 2 Diabetes Mellitus not taking insulin: a meta-analysis. Am J Manag. Care. 2008 Jul; 14(7):468-75.

9. Blonde L, Karter AJ. Current evidence regarding the value of self-monitored blood glucose testing. Am J Med. 2005 Sep; 118(9):20-6.

10. Sociedade Brasileira de Diabetes. Diretrizes da Sociedade Brasileira de Diabetes: tratamento e acompanhamento do Diabetes Mellitus. São Paulo (SP): SBD; 2007.

11. Sociedade Brasileira de Diabetes. Automonitorização glicêmica e monitorização contínua da glicose. Posicionamento Oficial SBD n. 1. Rev Bras Med. 2006; 1(supl)1-12.

12. Dailey G. Assessing glycemic control with selfmonitoring of blood glucose and hemoglobin A1c measurements. Mayo Clin Proc. 2007 Fev; 82(2):22936.

13. Saudek CD, Derr RL, Kalyani RR. Assessing glycemia in diabetes using self-monitoring blood glucose and hemoglobin A1c. JAMA. 2006 Apr; 295(14):1688-97.

14. Davis WA, Bruce DG, Davis TME. Is self-monitoring of blood glucose appropriate for all type 2 diabetic patients? The Fremantle diabetes study. Diabetes Care. 2006 Aug; 29(8):1764-70.

15. Goldstein DE, Little RR, Lorenz RA, Malone, JI, Nathan, D, Peterson CM, et al. Tests of glycemia in diabetes. Diabetes Care. 2004 Jul; 27(7):1761-73.

16. Rodrigues FFL, Zanetti ML, Santos MA, Martins TA, Sousa VD, Teixeira CRS. Knowledge and attitude: important components in diabetes education. Rev Latino Am Enfermagem. 2009 Jul-Ago; 17(4):468-73.

17. Meigs JB, Nathan DM, D'Agostino RB, Wilson PW. Fasting and postchallenge glycemia and cardiovascular disease risk: the Framingham offspring study. Diabetes Care. 2002 Oct; 25(10):184550.

18. Bergental RM, Gavin JR. The role of self-monitoring of blood glucose in the care of people with diabetes: report of a global consensus conference. Am J Med. 2005 Sep; 118(Suppl 9A):1-6.

19. Schwedes U, Siebolds M, Mertes G. Meal-related structured selfmonitoring of blood glucose: effect on diabetes control in non-insulin-treated type 2 diabetic patients. Diabetes Care. 2002 Nov; 25(11):1928-32.

20. Stratton IM, Adler AI, Neil AW, Matthews DR, Manley SE, Cull CA, et al. Association of glycaemia with macrovascular and microvascular complications of type 2 diabetes (UKPDS 35): prospective observational study. Br Med J. 2000 Ago; 321(7258):405-12.

21. Hay LC, Wilmshurst EG, Fulcher G. Unrecognized hypo- and hyperglycemia in well-controlled patients with type 2 Diabetes Mellitus: the results of 
continuous glucose monitoring. Diabetes Technol Ther. 2003 Jan; 5(1):19-26.

22. Silva ASB, Santos MA, Teixeira CRS, Damasceno MMC, Camilo J, Zanetti ML. Avaliação da atenção em Diabetes Mellitus em uma unidade básica distrital de saúde. Texto Contexto Enferm. 2011
Jul-Set; 20(3):512-18.

23. Silva ARV, Zanetti ML, Forti AC, Freitas RWJF, Hissa MN, Damasceno MMC. Avaliação de duas intervenções educativas para a prevenção do Diabetes Mellitus tipo 2 em adolescentes. Texto Contexto Enferm. 2011 Out-Dez; 20(4):782-7. 